University of Wollongong

Research Online

Australian Institute for Innovative Materials -

Papers

Australian Institute for Innovative Materials

$1-1-2012$

\title{
Magnetic properties and microstructures of iron oxide@mesoporous silica core-shell composite for applications in magnetic dye separation
}

Weichang Hao

University Of Wollongong,Beihang University

Yang Xi

Beihang University

Jingwei Hu

Beihang University

Tianmin Wang

Beihang University

Yi Du

University of Wollongong, ydu@uow.edu.au

See next page for additional authors

Follow this and additional works at: https://ro.uow.edu.au/aiimpapers

Part of the Engineering Commons, and the Physical Sciences and Mathematics Commons

Research Online is the open access institutional repository for the University of Wollongong. For further information contact the UOW Library: research-pubs@uow.edu.au 


\title{
Magnetic properties and microstructures of iron oxide@mesoporous silica core- shell composite for applications in magnetic dye separation
}

\author{
Abstract \\ "In this report, hollow mesoporous silica (HMS) and iron oxide-hollow mesoporous silica (FexOy@HMS) \\ core-shell composite were prepared by a one-step facile fabrication method. Transmission electron \\ microscopy, X-ray diffraction, $\mathrm{N}-2$ adsorption-desorption isotherms, and vibrating sample magnetometer \\ were used to characterize the morphology, microstructure, and magnetic properties of the HMS and core- \\ shell composite. The magnetic separability of FexOy@HMS core-shell composite was tested in \\ Rhodamine B (Rh. B) dye solution. The results indicate that the core-shell composite can absorb Rh. B \\ dyes molecules effectively up to $90.1 \%$. (C) 2012 American Institute of Physics. [doi:10.1063/1.3670049]"

\section{Keywords} \\ silica, separation, mesoporous, composite, oxide, applications, iron, microstructures, properties, magnetic, \\ shell, core, dye \\ Disciplines \\ Engineering | Physical Sciences and Mathematics

\section{Publication Details} \\ Hao, W., Xi, Y., Hu, J., Wang, T., Du, Y. \& Wang, X. L. (2012). Magnetic properties and microstructures of \\ iron oxide@mesoporous silica core-shell composite for applications in magnetic dye separation. Journal \\ of Applied Physics, 111 (7), 07B301-1-07B301-2.

\section{Authors} \\ Weichang Hao, Yang Xi, Jingwei Hu, Tianmin Wang, Yi Du, and X L. Wang
}




\section{AIP Applied Physics}

\section{Magnetic properties and microstructures of iron oxide@mesoporous silica core-shell composite for applications in magnetic dye separation}

Weichang Hao, Yang Xi, Jingwei Hu, Tianmin Wang, Y. Du et al.

Citation: J. Appl. Phys. 111, $07 B 301$ (2012); doi: 10.1063/1.3670049

View online: http://dx.doi.org/10.1063/1.3670049

View Table of Contents: http://jap.aip.org/resource/1/JAPIAU/v111/i7

Published by the American Institute of Physics.

\section{Related Articles}

Compositionally tunable three-dimensional nano-seeding assembly in $\mathrm{Fe}-\mathrm{LaSrFeO} 4$ nanostructure

J. Appl. Phys. 113, 064317 (2013)

Control of dissipation in superconducting films by magnetic stray fields

Appl. Phys. Lett. 102, 052601 (2013)

Room temperature reversible tuning of magnetism of electrolyte-gated La0.75Sr0.25MnO3 nanoparticles J. Appl. Phys. 113, 033913 (2013)

Nanotube wall thickness dependent magnetization reversal properties of NiFe nanotubes

J. Appl. Phys. 113, 024315 (2013)

Effect of milling parameters on SmCo5 nanoflakes prepared by surfactant-assisted high energy ball milling J. Appl. Phys. 113, 013913 (2013)

\section{Additional information on J. Appl. Phys.}

Journal Homepage: http://jap.aip.org/

Journal Information: http://jap.aip.org/about/about_the_journal

Top downloads: http://jap.aip.org/features/most_downloaded

Information for Authors: http://jap.aip.org/authors

\section{ADVERTISEMENT}

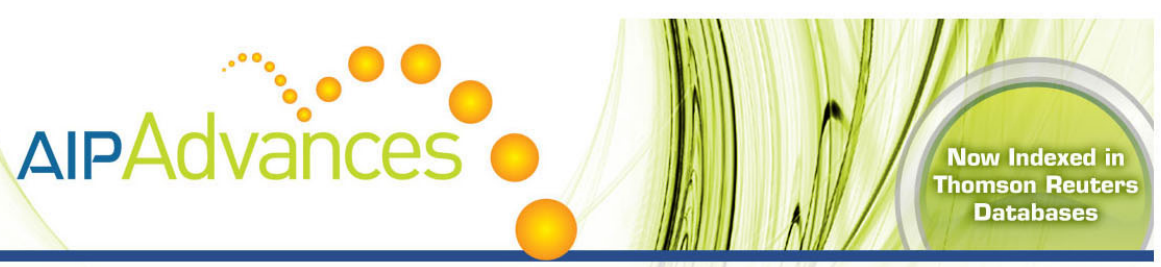

\section{Explore AIP's open access journal: Rapid publication \\ - Article-level metrics \\ Post-publication rating and commenting}




\title{
Magnetic properties and microstructures of iron oxide@mesoporous silica core-shell composite for applications in magnetic dye separation
}

\author{
Weichang Hao, ${ }^{1,2, a)}$ Yang Xi, ${ }^{1}$ Jingwei Hu, ${ }^{1}$ Tianmin Wang, ${ }^{1}$ Y. Du, ${ }^{2}$ and X. L. Wang ${ }^{2}$ \\ ${ }^{1}$ Center of Materials Physics and Chemistry, Beihang University, Beijing 100191, People's Republic of China \\ ${ }^{2}$ Institute for Superconducting and Electronic Materials (ISEM), University of Wollongong, Wollongong, \\ NSW 2522, Australia
}

(Presented 2 November 2011; received 21 September 2011; accepted 3 October 2011; published online 6 February 2012)

\begin{abstract}
In this report, hollow mesoporous silica (HMS) and iron oxide-hollow mesoporous silica $\left(\mathrm{Fe}_{\mathrm{x}} \mathrm{O}_{\mathrm{y}} @ \mathrm{HMS}\right)$ core-shell composite were prepared by a one-step facile fabrication method. Transmission electron microscopy, $\mathrm{X}$-ray diffraction, $\mathrm{N}_{2}$ adsorption-desorption isotherms, and vibrating sample magnetometer were used to characterize the morphology, microstructure, and magnetic properties of the HMS and core-shell composite. The magnetic separability of $\mathrm{Fe}_{\mathrm{x}} \mathrm{O}_{\mathrm{y}} @ \mathrm{HMS}$ core-shell composite was tested in Rhodamine B (Rh.B) dye solution. The results indicate that the core-shell composite can absorb Rh.B dyes molecules effectively up to 90.1\%. (C) 2012 American Institute of Physics. [doi:10.1063/1.3670049]
\end{abstract}

\section{INTRODUCTION}

Hollow mesoporous (HM) materials exhibit attractive physical and chemical properties, such as large adsorption capacity, good selectivity, and high catalytic activity, because of their high surface area, well-defined porous structure, and large tunable inner hollow size. ${ }^{1-3}$ The comparatively large inner hollow core provides potential carrier space, and the mesoporous shell provides the passage between the inside and the outside. HM materials have potential applications in absorbents, ${ }^{4}$ drug delivery, ${ }^{5}$ and catalyst support. ${ }^{6}$ The absorbents are broadly used in water purification by adsorption of pollutants due to their simplicity and low cost. ${ }^{7}$ The microstructure of HM materials is suitable for absorbents. However, it is so far still a challenge to separate HM materials from solution after purification, which possibly induces a secondary source of environmental pollution. The development of a facile separation method is very important for mesoporous absorbents in industrial applications. ${ }^{8}$ Recently, it was found that incorporating magnetic nanoparticles (MNs) into HM materials can provide a new strategy to develop novel absorbents for environmental purification., ${ }^{9} 10$ The MNs@HM coreshell structure combines the advantages of both mesoporous materials and magnetic particles, in which the mesoporous shell can effectively absorb pollutant molecules due to its high surface area and uniform pores, and the magnetic particles simplify the separation process in the liquid-phase system on application of an external magnetic field. Some efforts have been made to develop MNs@HM core-shell materials for absorbent application. It has been reported that $\mathrm{Fe}_{3} \mathrm{O}_{4} @ \mathrm{SiO}_{2}$ core-shell materials could be used as an absorbent for 1,1bis(4-chlorophenyl)-2,2,2-trichloroethane (DDT) Methylene Blue (MB), Acridine Orange (AC), and Rhodamine B (Rh.B) dyes, respectively. ${ }^{8,11,12}$ Hollow mesoporous carbon spheres with magnetic cores were also found to show good adsorption property properties for bilirubin. ${ }^{13}$

\footnotetext{
a) Author to whom correspondence should be addressed. Electronic mail: whao@buaa.edu.cn.
}

The conventional approaches to fabricating the MNs@HM core-shell nanostructures are the coating method and infiltration method. ${ }^{8,11-13}$ One important process in both approaches is the removal of the by-products or purification of products, which complicates the preparation and limits their applications. Cracked hollow nanostructures are also unavoidable during the synthesis process. In this work, we report the adsorption properties of $\mathrm{Fe}_{\mathrm{x}} \mathrm{O}_{\mathrm{y}} @ \mathrm{HMS}$ core-shell nanoparticles prepared by a one-step fabrication method. The microstructures and magnetic properties of the hollow mesoporous silica (HMS) and the $\mathrm{Fe}_{\mathrm{x}} \mathrm{O}_{\mathrm{y}} @ \mathrm{HMS}$ core-shell composite were studied. The adsorption properties and magnetic separability of $\mathrm{Fe}_{\mathrm{x}} \mathrm{O}_{\mathrm{y}} @ \mathrm{HMS}$ core-shell composite were tested in Rh.B dye solution.

\section{EXPERIMENTAL}

$\mathrm{FeCl}_{2}, \mathrm{FeCl}_{3}$, tetraethyl orthosilicate (TEOS), cetyltrimethyl ammonium bromide (CTAB), ammonia, and ethanol were obtained from Beijing Chemical Reagent Corporation of the Chinese Medicine Group. All materials were of analytical grade and were used as received without any further purification. $0.1 \mathrm{~g} \mathrm{FeCl}_{2}$ and $0.2 \mathrm{~g} \mathrm{FeCl}_{3}$ were dissolved into $20 \mathrm{ml}$ $\mathrm{H}_{2} \mathrm{O}$, which was then added to a $40 \mathrm{ml}$ ethanol solution containing $0.1 \mathrm{~g}$ CTAB and $3 \mathrm{ml}$ TEOS. The mixed solution was then added into $200 \mathrm{ml} 0.225 \mathrm{M}$ ammonia under vigorous magnetic stirring at room temperature. A brown precipitate was formed and collected after aging the suspension for $2 \mathrm{~h}$. The product was calcined at $600{ }^{\circ} \mathrm{C}$ with a heating rate of $1{ }^{\circ} \mathrm{C} \mathrm{min}^{-1}$ under $\mathrm{N}_{2}$ atmosphere. The sample was outgassed at $300{ }^{\circ} \mathrm{C}$ under $\mathrm{N}_{2}$ atmosphere for $3 \mathrm{~h}$ prior to the measurement.

$\mathrm{X}$-ray diffraction (XRD) and small angle XRD (SAXRD) patterns were collected on a Rigaku RINT D/Max-2400 powder diffraction system using $\mathrm{Cu} \mathrm{K} \alpha$ radiation at $1.54 \AA$. Nitrogen sorption experiments were performed at $77 \mathrm{~K}$ on a Micromeritics ASAP 2010 system. Transmission electronic microscopy (TEM) measurements were performed on a JEOL $2100 \mathrm{~F}$ microscope operated at $200 \mathrm{kV}$. All samples subjected to TEM measurements were ultrasonically dispersed in methanol and drop-cast onto copper grids. The magnetic properties 
were characterized by a vibrating sample magnetometer (VSM; LakeShore7410) at room temperature. The magnetic separability of $\mathrm{Fe}_{\mathrm{x}} \mathrm{O}_{\mathrm{y}} @ \mathrm{HMS}$ was characterized by adsorption of Rh.B solution. In the measurement, $0.5 \mathrm{~g} \mathrm{Fe}_{\mathrm{x}} \mathrm{O}_{\mathrm{y}} @ \mathrm{HMS}$ was added into $250 \mathrm{~mL} 1 \mathrm{mg} / \mathrm{L}$ Rh.B. Ultraviolet-visible (UV-Vis) absorption spectra of the solution were collected on a Hitachi U3010 spectrophotometer after 1 min adsorption.

\section{RESULTS AND DISCUSSION}

Figure 1 shows the XRD pattern of the $\mathrm{Fe}_{\mathrm{x}} \mathrm{O}_{\mathrm{y}} @ \mathrm{HMS}$ core-shell nanocomposite. The XRD peaks are indexed with $\mathrm{Fe}_{3} \mathrm{O}_{4}$ (Ref. 14) and $\gamma-\mathrm{Fe}_{2} \mathrm{O}_{3}{ }^{15}$ The broad peak at $22^{\circ}$ can be assigned to the characteristic refection from amorphous $\mathrm{SiO}_{2}$. The XRD results indicate that $\mathrm{Fe}_{3} \mathrm{O}_{4}, \gamma-\mathrm{Fe}_{2} \mathrm{O}_{3}$, and amorphous silica were formed simultaneously. TEM images of the microstructures and morphologies of HMS and of the composite are shown in Fig. 2. We can see that the mesoporous silica (Fig. 2(a)) consists of hollow spheres 100-220 nm in diameter and about $25 \mathrm{~nm}$ in shell thickness. For the $\mathrm{Fe}_{\mathrm{x}} \mathrm{O}_{\mathrm{y}} @ \mathrm{HMS}$ sample (Fig. 2(b)), it can be seen that there is a strong contrast difference in all of the spheres between the dark centers and the bright edges of the spheres, confirming that the $\mathrm{Fe}_{\mathrm{x}} \mathrm{O}_{\mathrm{y}}$ particles completely fill the hollow silica particles when ferric halide precursors are incorporated into the reaction system. The thickness of the mesoporous shell remains unchanged. The observed blurry silica shells indicate the decay of the mesoporous structure symmetry, which is due to the incorporation of iron oxide.

The adsorption properties of core-shell materials depend on the mesoporous structure of the silica shell. The porous structure of the as-prepared particles was assessed by SAXRD and $\mathrm{N}_{2}$ adsorption isotherms. From the SAXRD patterns (as shown in Fig. 3(a)), the intensity of the (100) peak decreases while the full width at half maximum (FWHM) increases, indicating the decay of the mesoporous structure symmetry. ${ }^{16}$ This is in accordance with the results observed from TEM images. The nitrogen absorption isotherm provides further information on the hollow core variation. As shown in Fig. 3(b), the $\mathrm{N}_{2}$ adsorption-desorption isotherms

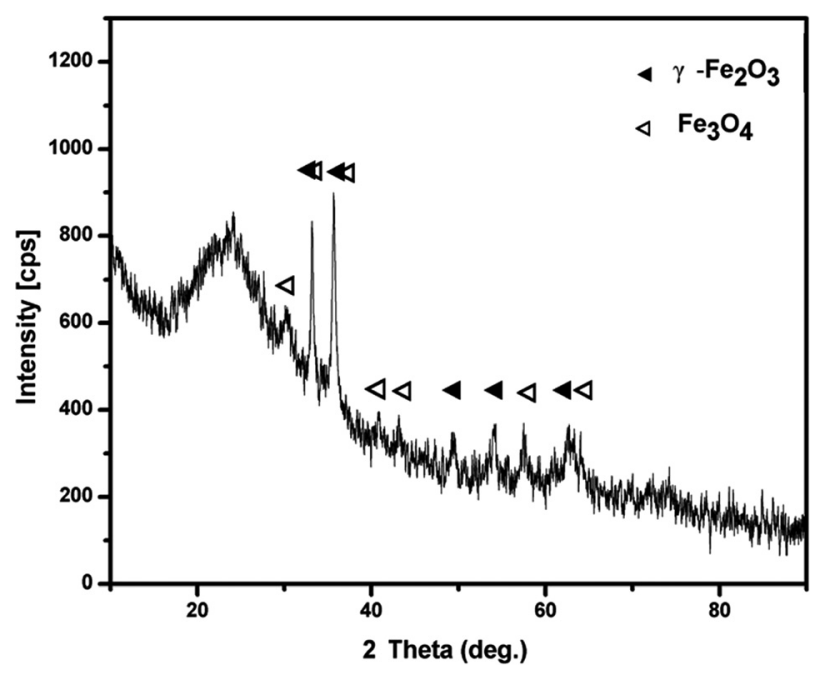

FIG. 1. XRD pattern of $\mathrm{Fe}_{\mathrm{x}} \mathrm{O}_{\mathrm{y}} @ \mathrm{HMS}$ core-shell structure.
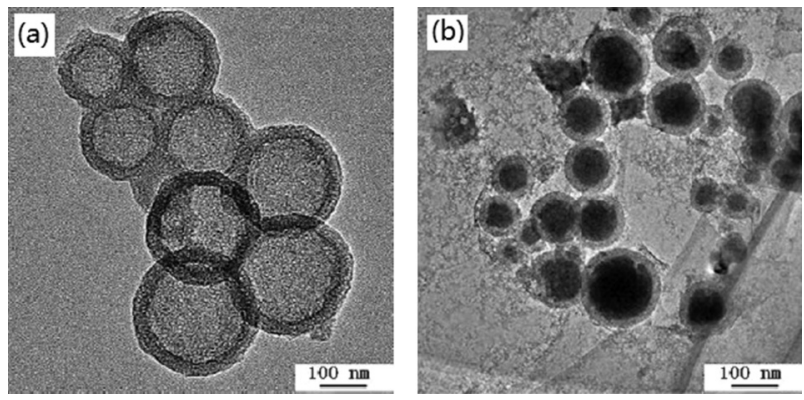

FIG. 2. TEM images of (a) HMS and (b) $\mathrm{Fe}_{\mathrm{x}} \mathrm{O}_{\mathrm{y}} @ \mathrm{HMS}$ core-shell composite.

of the samples present typical type-IV adsorption. ${ }^{17}$ which show an apparent capillary condensation step at relative pressure $\left(\mathrm{P} / \mathrm{P}_{0}\right)$ of 0.3 . The pore size was calculated as 2.4 $\mathrm{nm}$ by the Barrett-Joyner-Halenda (BJH) method. H4-type hysteresis loops ${ }^{18}$ at relative pressure $\left(\mathrm{P} / \mathrm{P}_{0}\right)$ above 0.5 for the samples suggest that the inner hollow core and the outer surface are connected through the mesoporous structure, which results in the adsorption of $\mathrm{N}_{2}$ molecules in the hollow core. The reduction of the H4-type loop for the composite is ascribed to the incorporation of $\mathrm{Fe}_{\mathrm{x}} \mathrm{O}_{\mathrm{y}}$ particles into the inner hollow spaces. The decay of symmetry and the occupation of
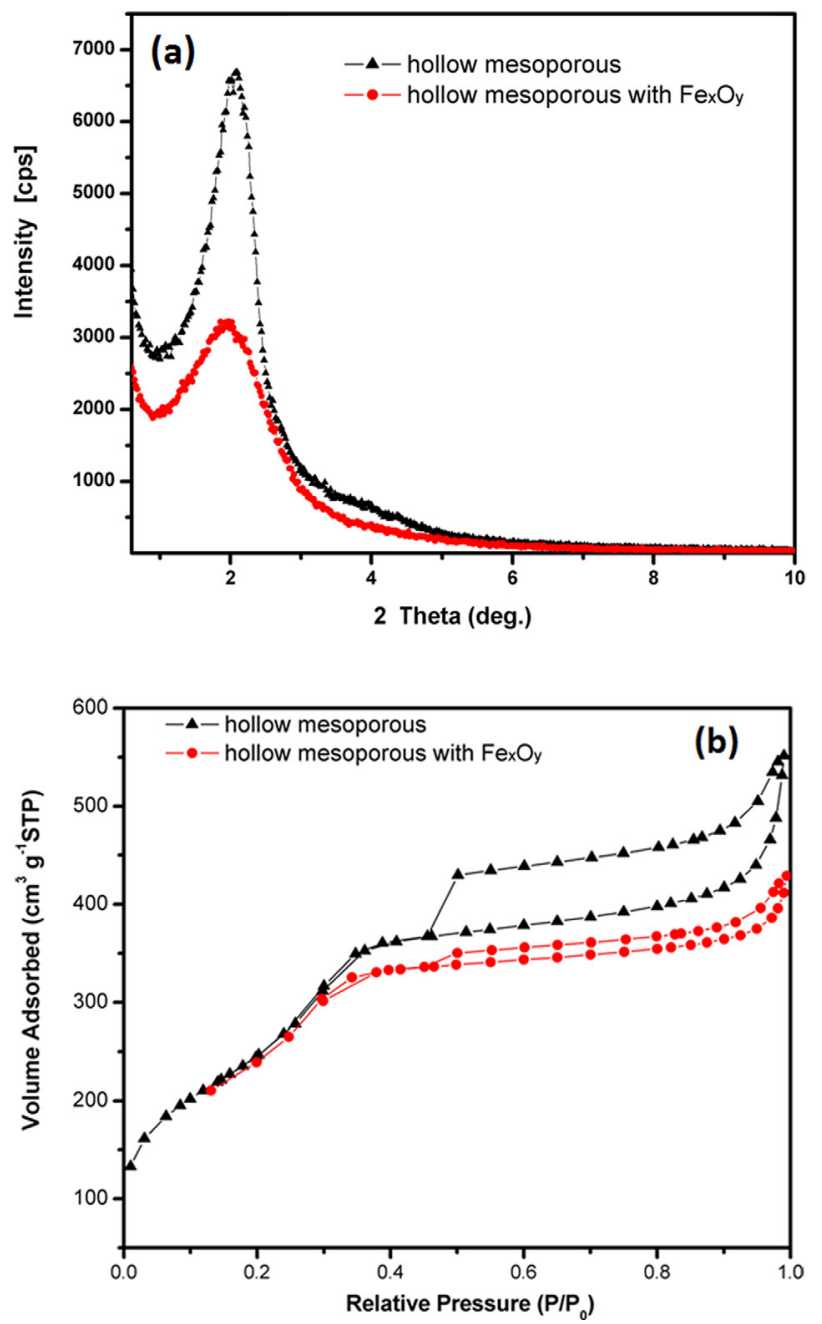

FIG. 3. (Color online) (a) SAXRD patterns and (b) $\mathrm{N}_{2}$ adsorption isotherms of HMS and $\mathrm{Fe}_{\mathrm{x}} \mathrm{O}_{\mathrm{y}} @ \mathrm{HMS}$ core-shell composites. 

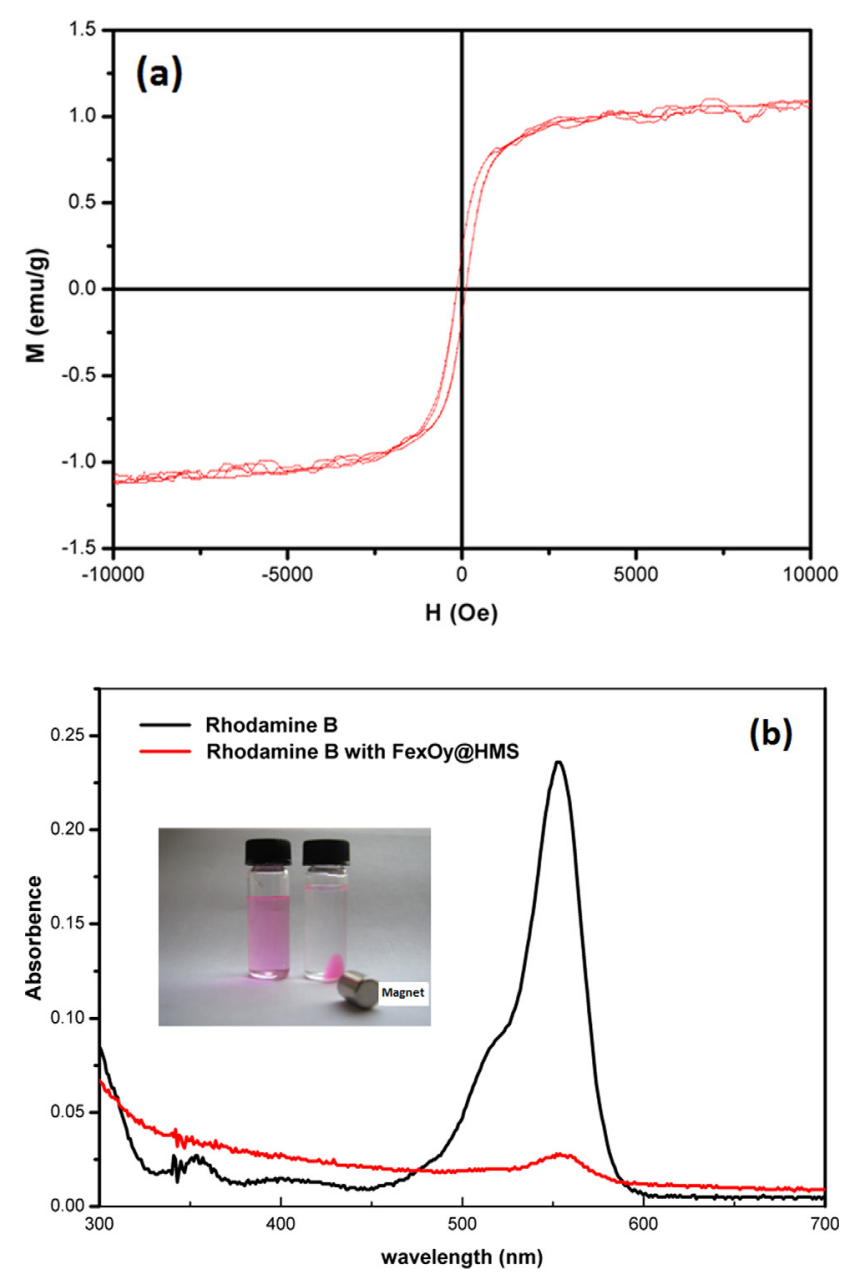

FIG. 4. (Color online) (a) M-H hysteresis loop measured at room temperature, (b) adsorption test for Rh.B dye solution, with the inset illustrating the magnetic separation of absorbent from the final solution by an external magnetic field.

inner spaces lead to reduction of the surface area of composite sample. The Brunauer-Emmett-Teller (BET) surface area is $896 \mathrm{~m}^{2} \mathrm{~g}^{-1}$ and $128 \mathrm{~m}^{2} \mathrm{~g}^{-1}$ for HMS and $\mathrm{Fe}_{\mathrm{x}} \mathrm{O}_{\mathrm{y}} @ \mathrm{HMS}$ composite, respectively. The surface area of the core-shell material is quite large, even if it shows a decrease compared with HMS.

The separation performance of the $\mathrm{Fe}_{\mathrm{x}} \mathrm{O}_{\mathrm{y}} @ \mathrm{HMS}$ composite depends on the magnetic properties of the $\mathrm{Fe}_{\mathrm{x}} \mathrm{O}_{\mathrm{y}}$ core. The magnetization $(\mathrm{M})$ as a function of magnetic field $(\mathrm{H})$ was measured for $\mathrm{Fe}_{\mathrm{x}} \mathrm{O}_{\mathrm{y}} @ \mathrm{HMS}$ at room temperature, as shown in Fig. 4(a). There is a clear M-H hysteresis loop with saturated magnetization of $1.1 \mathrm{emu} / \mathrm{g}$, which indicates that the core-shell material has a good response to an external magnetic field. The magnetic separability of $\mathrm{Fe}_{\mathrm{x}} \mathrm{O}_{\mathrm{y}} @ \mathrm{HMS}$ was tested by adsorption of Rh.B solution, which is regarded as general dye pollution waste. After $1 \mathrm{~min}$ adsorption, a magnet was placed near the waste solution with $\mathrm{Fe}_{\mathrm{x}} \mathrm{O}_{\mathrm{y}} @ \mathrm{HMS}$ particles, A clear solution was obtained immediately, as shown in inset of Fig. 4(b). The separated solution was characterized by UV-Vis absorption spectra of the Rh.B solution before and after magnetic separation (Fig. 4(b)).
The adsorption capability can be expressed by the concentration variation of $\left(\mathrm{C}_{0}-\mathrm{C}\right) / \mathrm{C}_{0}$ (where $\mathrm{C}_{0}$ is the initial concentration and $\mathrm{C}$ is the final concentration of $\mathrm{Rh} . \mathrm{B}$ dye). The concentration variation is about $90.1 \%$, which indicates that the core-shell material exhibits a high adsorption capacity. The results demonstrate that $\mathrm{Fe}_{\mathrm{x}} \mathrm{O}_{\mathrm{y}} @ \mathrm{HMS}$ core-shell material can be a potential candidate as a magnetic separation absorbent.

\section{CONCLUSIONS}

In summary, we have successfully fabricated $\mathrm{Fe}_{\mathrm{x}} \mathrm{O}_{\mathrm{y}} @ \mathrm{HMS}$ core-shell composite with uniform shell thickness of $25 \mathrm{~nm}$ via a facile one-step method. The inner iron oxide core has a good response to external magnetic field. The high surface area and porous structure of the outer mesoporous silica shell leads to high adsorption capacity of the core-shell material. The magnetic separability of the $\mathrm{Fe}_{\mathrm{x}} \mathrm{O}_{\mathrm{y}} @ \mathrm{HMS}$ core-shell composite was confirmed by adsorption testing in Rh.B dye solution.

\section{ACKNOWLEDGMENTS}

This work was financially supported by the National Natural Science Foundation of China (Grant Nos. 51072012 and 50732004) and the Fundamental Research Foundation for the Central Universities (Grant No. YWF-11-03-Q-079). X.L.W. thanks the Australian Research Council for partial support of this work. W.H. also acknowledges financial support from the China Scholarship Council for his visit to the University of Wollongong.

${ }^{1}$ S. H. Han, W. G. Hou, J. Xu, and Z. M. Li, Colloid Polym. Sci. 282, 1286 (2004).

${ }^{2}$ Y. F. Zhu, J. L. Shi, H. R. Chen, W. H. Shen, and X. P. Dong, Micropor. Mesopor. Mater. 84, 218 (2005).

${ }^{3}$ S. B. Yoon, K. Sohn, J. Y. Kim, C.-H. Shin, J.-S. Yu, and T. Hyeon, Adv. Mater. 14, 19 (2002).

${ }^{4}$ L. M. Guo, J. T. Li, L. X. Zhang, J. B. Li, Y. S. Li, C. C. Yu, J. L. Shi, M. Ruan, and J. W. Feng, J. Mater. Chem. 18, 2733 (2008).

${ }^{5}$ Y. F. Zhu, J. L. Shi, W. H. Shen, X. P. Dong, J. W. Feng, M. L. Ruan, and Y. S. Li, Angew. Chem. Int. Ed. 44, 5083 (2005).

${ }^{6}$ B. Fang, J. H. Kim, C. Lee, and J. S. Yu, J. Phys. Chem. C 112, 639 (2008).

${ }^{7}$ C. Zubieta, M. B. Sierra, M. A. Morini, P. C. Schulz, L. Albertengo, and M. S. Rodríguez, Colloid Polym. Sci. 286, 377 (2008).

${ }^{8}$ W. Zhao, J. L. Gu, L. X. Zhang, H. R. Chen, and J. L. Shi, J. Am. Chem. Soc. 127, 8916 (2005).

${ }^{9}$ X. C. Fu, X. Chen, J. Wang, and J. H. Liu, Micropor. Mesopor. Mater. 139, 8 (2011).

${ }^{10}$ J. Liu, S. Z. Qiao, Q. H. Hu, and G. Q. Lu, Small 7, 425 (2011).

${ }^{11}$ H. Tian, J. J. Li, Q. Shen, H. L. Wang, Z. P. Hao, L. D. Zou, and Q. Hu, J. Hazard. Mater. 171, 459 (2009).

${ }^{12}$ Y. Y. Yin, S. X. Zhou, C. Min, and L. M. Wu, J. Colloid Interface Sci. 367, 527 (2011).

${ }^{13}$ L. M. Guo, X. Z. Cui, Y. S. Li, Q. J. He, L. X. Zhang, W. B. Bu, and J. L. Shi, Chem. Asian J. 4, 1480 (2009).

${ }^{14}$ JCPDS Card No. 65-3107.

${ }^{15}$ JCPDS Card No. 39-1346.

${ }^{16}$ Y. P. Zhai, Y. Q. Dou, X. X. Liu, B. Tu, and D. Y. Zhao, J. Mater. Chem. 19, 3292 (2009).

${ }^{17}$ H. Naono, M. Hakuman, T. Tanaka, N. Tamura, and K. Nakai, J. Colloid Interface Sci. 225, 411 (2000).

${ }^{18}$ M. Thommes, Chem. Ing. Tech. 82, 1059 (2010). 